\title{
Analysis of urinary stone constituents using powder X-ray diffraction and FT-IR
}

\author{
PRAGNYA A BHATT and PARIMAL PAUL* \\ Analytical Science Division, Central Salt and Marine Chemicals Research Institute, \\ G B Marg, Bhavnagar 364002 \\ e-mail: ppaul@csmcri.org
}

MS received 11 December 2007; revised 13 February 2008

\begin{abstract}
Constituents of urinary stones obtained from various patients from western part of India, which is a highly urinary stone disease-prone area, have been analysed. Eight stones from four patients were collected through urologists and have been analysed using powder X-ray diffraction and FT-IR. Thermogravimetric analysis (TGA) and scanning electron microscopic (SEM) image of selected samples were also carried out. The analysis revealed that calcium oxalate monohydrate, which is also known as whewellite, is the common constituent of all of the stones, particularly at the initial stage of stone formation. However, multi phases viz. whewellite phase, and hydroxyl and carbonate apatite phases are also detected in the case of third and fourth patients, from where multiple stones were obtained. Interestingly, in these mixed phase stones the concentration of whewellite decreases with increasing the concentration of apatite phases. Thermal behaviour of the whewellite phase was studied by TGA and variable temperature XRD analysis. Morphology of the whewellite and apatite phases, examined by SEM image, has also been reported.
\end{abstract}

Keywords. Urinary stones; powder X-ray diffraction; calcium oxalate monohydrate; hydroxylapatite.

\section{Introduction}

Urinary stone disease which is also known as renal calculi or urolithiasis, ${ }^{1}$ causes substantial pain and occasional renal failure. It has affected man kind since $4800 \mathrm{BC}$, but disease mechanism is not yet fully understood till today. ${ }^{2,3}$ Urinary stones are hard solid pellets, and are found at three sites of urinary track (kidney, ureter and bladder). Finlayson reviewed several worldwide geographic surveys and stated the nation wide high incidence/low incidence areas. ${ }^{4} \mathrm{~A}$ number of researchers have made the survey of specific zone for a specific period and tried to understand the specificity of the urinary stone for the respective zone. ${ }^{5-9}$ Sex and age related composition of urinary stones have also been identified by Daudon et al. ${ }^{10}$ Etiological factors which are considered responsible for stone formation are metabolic disorder, ion transport within the intestinal track and kidney and diet including fluid intake. Geographical location, water quality, hot climate, occupation, stress, drug and bacteria induced factors are all external

\footnotetext{
*For correspondence
}

factors causing urinary stones. Considerable research in this area is being done to understand the three stages of stone formation, heterogeneous nucleation, crystal growth and crystal aggregation, and the role of modifiers (inhibitors, promoters and complexor) of the same in the stone formation phenomena. ${ }^{11}$

To understand the influence of environmental and etiological factors on growth of stones, it is essential to know the constituents of it. The composition of stones varies from patient to patient and also with time within the same patient. Western India (Saurashtra region of Gujarat state), which comes under the region of hot climate, low rain fall, and increased salinity of ground water, is a highly urinary stone diseaseprone area, however, no systematic study on urinary stone analysis of this region has been done. Advent of analytical tools has made it possible to examine and or identify the urinary stone constituents using various techniques. ${ }^{5,7,8-10,12,13} \mathrm{We}$ have undertaken a study on the analysis of constituents of urinary stones from various patients of this region with the aim that the data from a large number of patients may provide some idea about the factors, which cause high urinary stone disease of this region. In this 
Table 1. Details of samples collected from various patients.

\begin{tabular}{|c|c|c|c|c|c|}
\hline $\begin{array}{l}\text { Code number of } \\
\text { the patient }\end{array}$ & $\begin{array}{l}\text { Number of } \\
\text { stones }\end{array}$ & $\begin{array}{l}\text { Code of } \\
\text { the stones }\end{array}$ & $\begin{array}{l}\text { Food } \\
\text { habit }\end{array}$ & $\begin{array}{l}\text { Gender } \\
\text { and age }\end{array}$ & Stone removal procedure \\
\hline KSHP & 1 & KSHP1 & Vegetarian & Male, 50 & Natural excretion in the urine \\
\hline KSHIM & 1 & KSHIM & Vegetarian & Male, 55 & Shockwave lithotripsy \\
\hline KSN & 3 & $\begin{array}{l}\text { KSN1 } \\
\text { KSN2 } \\
\text { KSN3 }\end{array}$ & Vegetarian & Female, 45 & $\begin{array}{l}\text { Lithotripsy } \\
\text { Ureteroscopy } \\
\text { Natural excretion in the urine }\end{array}$ \\
\hline KSF & 3 & $\begin{array}{l}\text { KSF1 } \\
\text { KSF2 } \\
\text { KSF3 }\end{array}$ & Non-vegetarian & Female, 50 & $\begin{array}{l}\text { Shockwave lithotripsy } \\
\text { Shockwave lithotripsy } \\
\text { Shockwave lithotripsy }\end{array}$ \\
\hline
\end{tabular}

paper, we report analysis of eight samples obtained from different patients using powder X-ray diffraction, FT-IR, SEM and TGA analysis.

\section{Experimental}

\subsection{Materials}

All the eight urinary stone samples have been collected from the urologist of the Bhavnagar city after the surgery has been performed on the patient, or after spontaneous excretion of the stone. Details of samples collected from various patients are given in table 1. All stones have been dried for a week and were powdered before use for measurement. Multiple stones from the same patient have been powdered separately and then the analytical measurements have been performed. Calcium oxalate monohydrate and hydroxylapatite are purchased from Sigma-Aldrich chemical co (Fluka).

\subsection{Analytical measurements}

Powder X-ray diffraction analysis was performed on Philips X'Pert MPD X-ray diffractometer using $\mathrm{CuK}_{\alpha}$ radiation in the $2 \theta$ range of 10 to $60^{\circ}$. Variable temperature powder X-ray diffraction measurements have been performed using XRK reaction chamber at room temperature, and in the temperature range 100 to $800^{\circ} \mathrm{C}$ with step size of $100^{\circ} \mathrm{C}$ and heating rate of $20^{\circ} \mathrm{C} / \mathrm{min}$. in the $2 \theta$ range of 10 to $60^{\circ}$. Constituents present in the stones have been identified by comparing the measured diffractograms with JC_PDF (joint committee for powder Xray diffraction file), ICDD (international crystallographic diffraction data) database. Thermogravimetric analysis has been carried out for three stones on a Toledo Metler TGA system, with heating rate of $5^{\circ} \mathrm{C} / \mathrm{min}$, under nitrogen atmosphere. Scanning electron microscopic images were recorded on Carl Zeiss SMT LEO $1430 \mathrm{VP}$ with operating voltage of $5 \mathrm{kV}$ and $15 \mathrm{kV}$. Infrared spectra were recorded on a Perkin Elmer Spectrum GX FT-IR system using KBr pallet. Quantification of the apatite phase in the binary mixture of apatite and whewellite constituting stones was carried out by FT-IR following the procedure of Estepa and Daudon ${ }^{12}$ using (1).

$$
I=I_{1} v_{1} / I_{2} v_{2}=f(X \%)
$$

where $I=$ absorption ratio of selected band, $I_{1}$ and $I_{2}=$ intensity of the two selected bands/peaks, $v_{1}$ and $v_{2}=$ two representative wave numbers selected and $X=\%$ of the respective phase. For the apatite whewellite mixture, the intensities of the two reference absorption peaks $\left(v_{1}\right)$ at 1030 and $\left(v_{2}\right)$ at $1620 \mathrm{~cm}^{-1}$ (characteristic bands of apatite and whewellite phase respectively) for all of the mixed phased stones (KSN1, KSF1, KSF2, KSF3) were obtained from the infrared spectra and the intensity ratios were calculated using (1). Percentage of apatite phase in each sample was then determined using the calibration curve reported in the literature. ${ }^{12}$

\section{Results and discussions}

\subsection{Powder X-ray diffraction analysis}

On the basis of the search match analysis performed on the Powder X-ray diffraction data using JCPDFICDD database, constituents of all the eight stones have been identified and the results are summarized in table 2. Figure 1 shows diffractograms of four stones from three different patients labelled as KSHP1, KSHIM, KSN2 and KSN3. It may be noted that all of the four diffractograms are similar and consist of 
Table 2. Phase identification based on XRPD search match analysis.

\begin{tabular}{lllc}
\hline Name of the sample & Phase organization & Matched phases & JCPDF number \\
\hline KSHP1 & Well-organized & Whewellite $^{1}$ & $20-0231$ \\
KSHIM & Well-organized & Whewellite & $20-0231$ \\
KSN1 & Well-organized & Whewellite & $20-0231$ \\
& Poorly-organized & Hydroxyl apatite & $09-0432$ \\
KSN2 & Well-organized & Whewellite & $20-0231$ \\
KSN3 & Well-organized & Whewellite & $20-0231$ \\
KSF1 & Poorly-organized & Carbonateapatite & $21-0145$ \\
& Organized & Whewellite & $20-0231$ \\
KSF2 & Organized & Whewellite & $20-0231$ \\
& Poorly-organized & Hydroxylapatite & $09-0432$ \\
KSF3 & Organized & Whewellite & $20-0231$ \\
& Poorly-organized & Hydroxylapatite & $09-0432$ \\
\hline${ }^{1} \mathrm{CaC}_{2} \mathrm{O}_{4} \mathrm{H}_{2} \mathrm{O} ;{ }^{2}{ }^{2} \mathrm{Ca}_{5}\left(\mathrm{PO}_{4}\right)_{3}(\mathrm{OH}) ;{ }^{3} \mathrm{Ca}_{10}\left(\mathrm{PO}_{4}\right)_{5} \mathrm{CO}_{3}(\mathrm{OH}) \mathrm{F}$
\end{tabular}

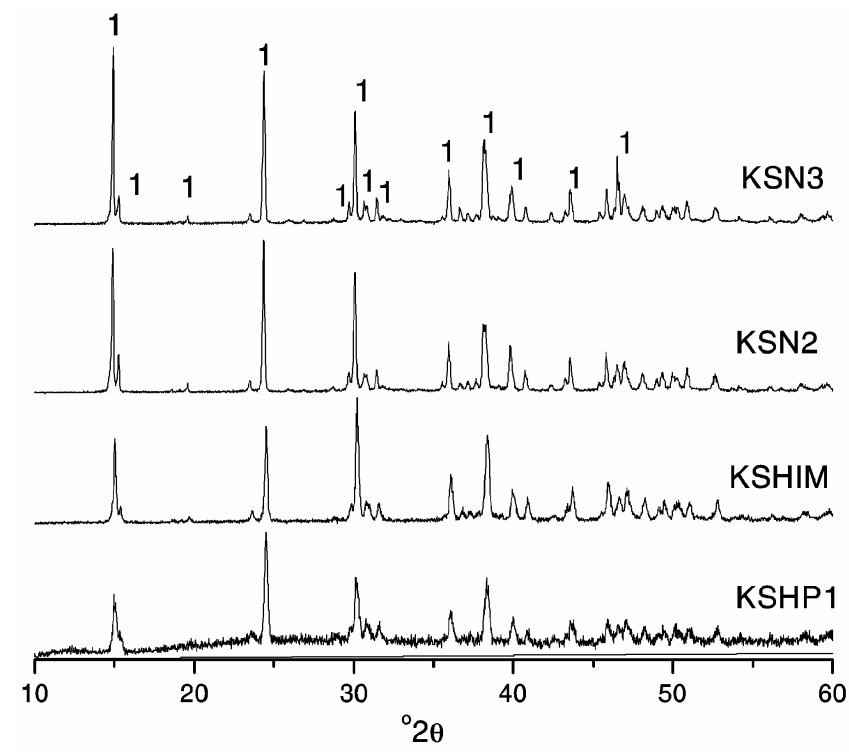

Figure 1. Diffractograms of stones containing whewellite phase (KSHP1, KSHIM, KSN2 and KSN3), peaks labelled as 1 in KSN3 corresponds to whewellite phase (minor peaks are not labelled for clarity).

sharp peaks. These peaks, labelled as 1 in KSN3, match well with the diffractogram of the standard sample of whewellite phase, suggesting that constituent of all of the four samples correspond to whewellite phase. After assignment of peaks for whewellite phase, no significant peak was left, which suggest high purity of these samples. It may be noted that the positions of the peaks $\left({ }^{\circ} 2 \theta\right)$ corresponding to whewellite phase in all of the four diffractograms match very well with each other, however, intensity ratios of these peaks vary from sample to sample, indicating variation in degree of crystallinity of these samples.

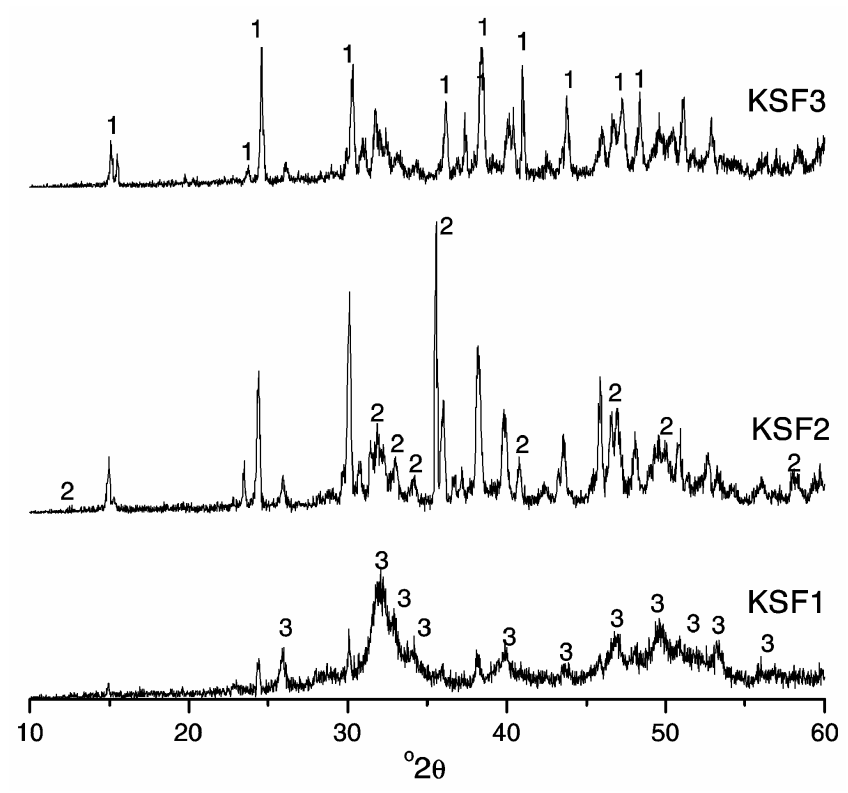

Figure 2. Diffractograms of stones containing mixed phases (KSF1, KSF2 and KSF3), major peaks corresponds to whewellite, hydroxylapatite and carbonate hydroxylapatite phases are labelled as 1,2 and 3, respectively (minor peaks are not labelled for clarity).

Figure 2 shows diffractograms of three stones KSF1, KSF2 and KSF3 from the same patient. They clearly show the presence of mixed constituents containing well-organized and also poorly-organized phases. The first one is a well-organized phase marked as 1 (whewellite) on KSF3 diffractogram, the second one is hydroxylapatite phase, labelled as 2 on KSF2, and the third one is a poorly-organized carbonate apatite phase labelled as 3 on KSF1. From figure 2, it is clear that the diffractogram of KSF3 is dominated 


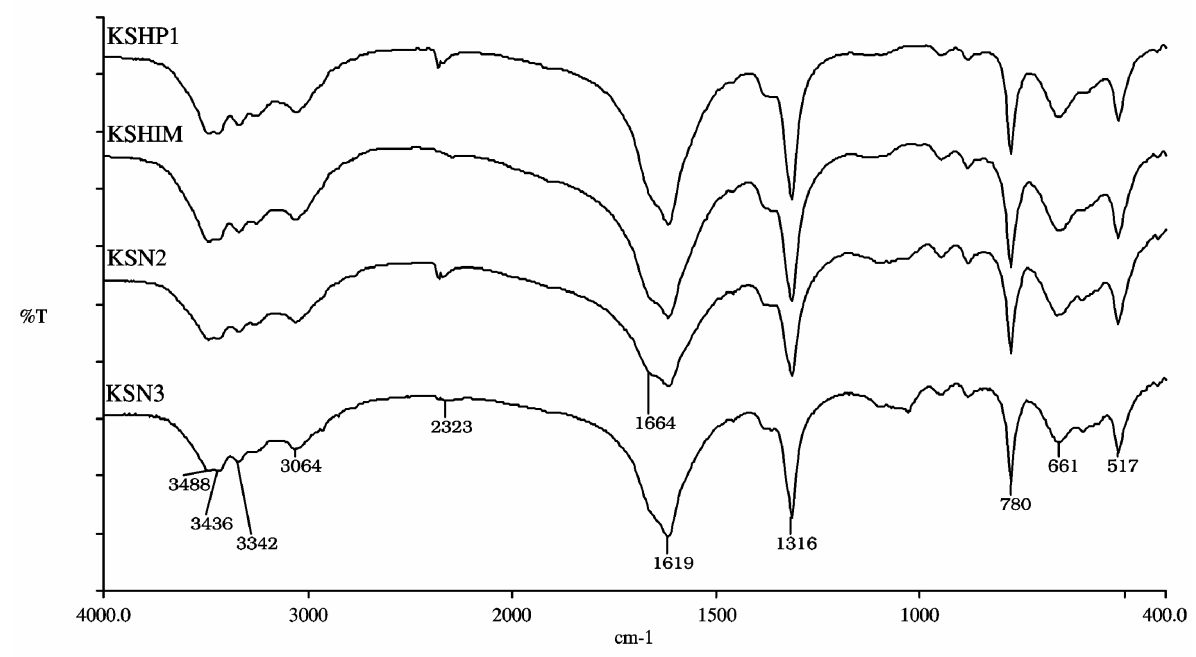

Figure 3. IR spectra of stones containing whewellite phase (KSHP1, KSHIM, KSN2 and KSN3).

by sharp peaks correspond to crystalline whewellite phase, however, these sharp peaks are minor component in KSF1, which is dominated by broad unresolved peaks correspond to the poorly crystalline carbonate apatite phase. The diffractogram of KSF2 shows the presence of whewellite and hydroxylapatite (2) phases, overlapping of some of the peaks of whewellite and hydroxylapatite phases made it difficult to identify the major component, however significant amount of both these phases are present in this stone.

\subsection{FT-IR analysis}

Infrared spectra of the samples KSHP1, KSHIM, KSN2 and KSN3 are shown in figure 3. All of the spectra are similar, and exhibit poorly resolved four bands in the range $3500-3200 \mathrm{~cm}^{-1}$, a weak band at $3064 \mathrm{~cm}^{-1}$, a strong band around $1620 \mathrm{~cm}^{-1}$, two moderate intensity sharp bands at 1316 and $780 \mathrm{~cm}^{-1}$, and two weak bands at 661 and $517 \mathrm{~cm}^{-1}$. These spectra are similar to that found for calcium oxalate monohydrate, ${ }^{13}$ indicating that they correspond to whewellite phase, which is consistent with the observation noted in powder XRD. The bands in the range $3500-3200 \mathrm{~cm}^{-1}$ are due to symmetric and asymmetric stretch of the water molecule, whereas the strong peaks around $1620 \mathrm{~cm}^{-1}$ and the weak band at $661 \mathrm{~cm}^{-1}$ can be assigned to the bending and wagging modes of the water molecule. ${ }^{12-14}$ The bands at $1664,1316,780$ and $517 \mathrm{~cm}^{-1}$ are due to $\sigma_{a}(\mathbf{C}=\mathbf{O}), \sigma_{s}(\mathbf{C}=\mathbf{O}), \delta(\mathrm{O}-\mathbf{C}=\mathbf{O})$ and $\sigma(\mathrm{Ca}-\mathrm{O})$, fre- quencies of the oxalato moiety. ${ }^{12,14}$ The infrared spectra of the three samples from same patient (KSF1, KSF2 and KSF3) containing mixed phases have also been recorded and displayed in figure 4 . All these spectra show the bands corresponding to calcium oxalate monohydrate (whewellite phase), as shown in figure 4, however, intensities of these bands decrease in the order KSF3 $>$ KSF2 $>$ KSF 1 and for KSF1 the whewellite phase is the minor component. It may be noted that in these spectra a few new bands are growing in and they become major component in KSF1. These bands are a weak band at $1423 \mathrm{~cm}^{-1}$, two strong bands at 1096 and $1037 \mathrm{~cm}^{-1}$ and two sharp bands at 605 and $566 \mathrm{~cm}^{-1}$. The IR spectra of pure hydroxyapatite has also been recorded, it shows three major peaks for phosphate anion at 1032, 603 and $565 \mathrm{~cm}^{-1}$, which can be assigned to $v_{3}\left(\mathrm{PO}_{4}\right)$, lattice mode and $v_{4}\left(\mathrm{PO}_{4}\right)$, respectively. ${ }^{12}$ Therefore, the strong band at $1037 \mathrm{~cm}^{-1}$ and the sharp bands at 605 and $566 \mathrm{~cm}^{-1}$ are due to phosphate anion. The presence of phosphorus in the hydroxyapatite phase has also been confirmed from EDAX study. The other two new bands in IR at 1423 and $1557 \mathrm{~cm}^{-1}$ are assigned to $v(\mathrm{CO})$ of the carbonate apatite phase. $^{12}$

The band corresponds to the $\mathrm{OH}^{-}$group of the hydroxyapatite phase could not be assigned definitely as number of peaks overlapped in the region 3500$3300 \mathrm{~cm}^{-1}$ and finally became broad in the sample KSF1. The percentage of the apatite phase in the mixed phase stones KSF1, KSF2, KSF3 and KSN1 are calculated by equation (1) with the help of the 


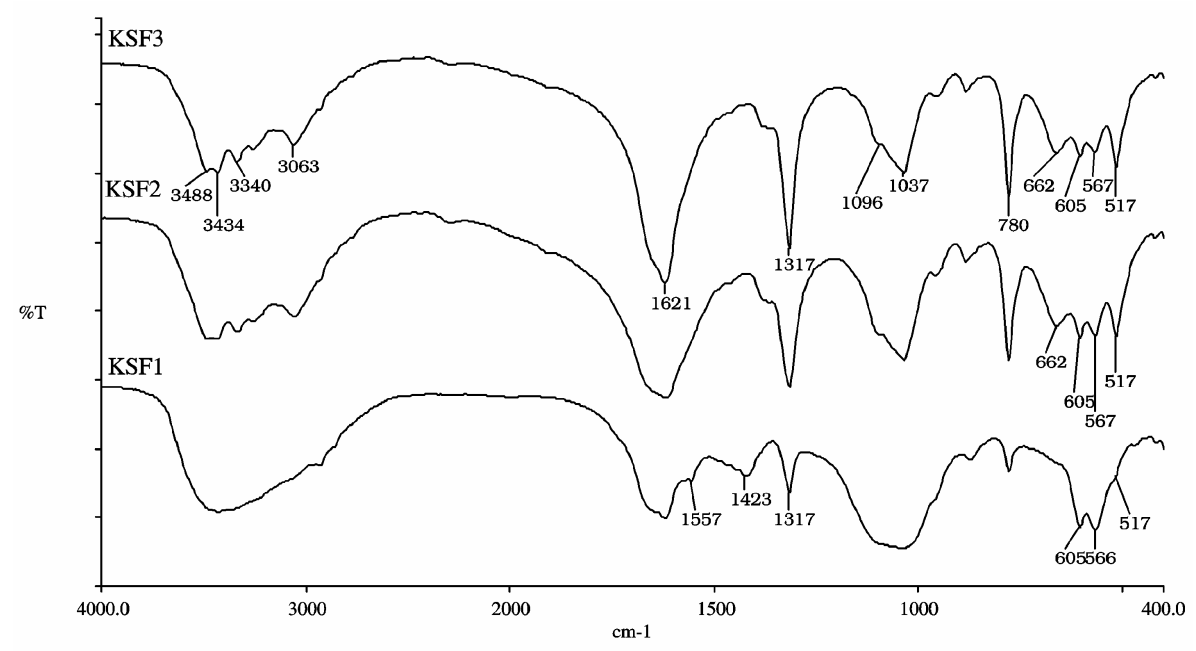

Figure 4. IR spectra of stones (KSF3, KSF2 and KSF1) containing mixed phase (whewellite, hydroxylapatite and carbonatehydroxylapatite).

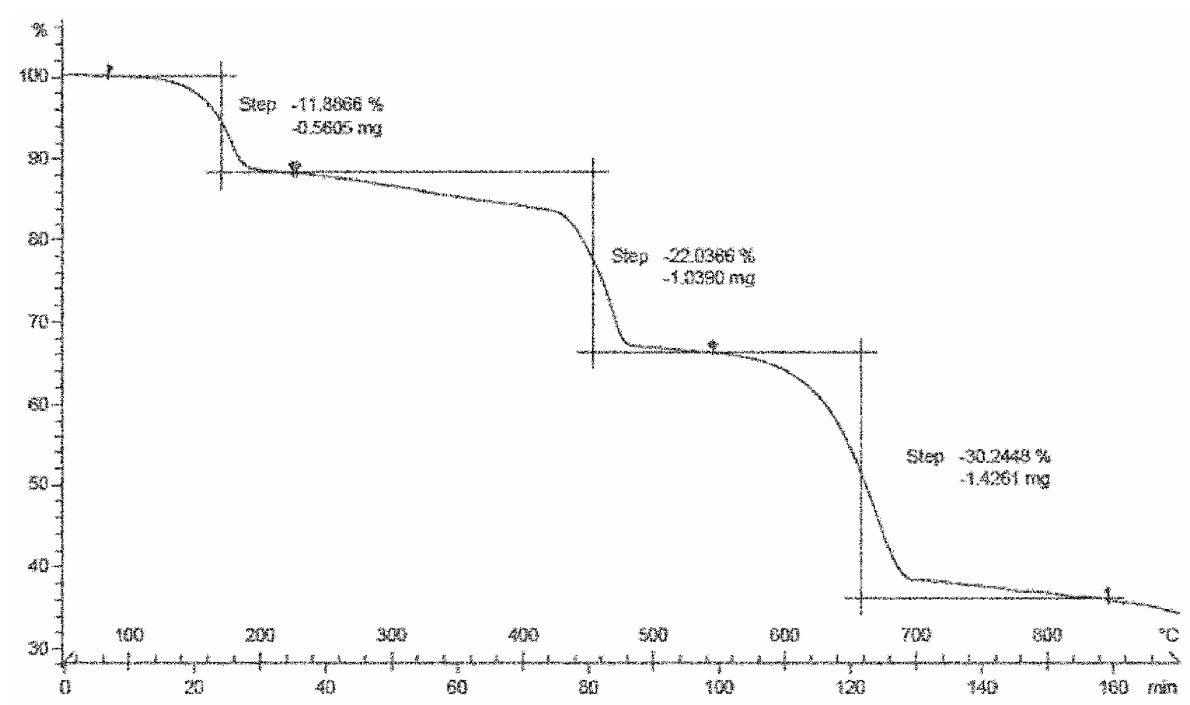

Figure 5. Thermogravimetric analysis of a whewellite phase (KSN2).

calibration curve ${ }^{13}$ using intensity values of the two IR bands at $1030\left(v_{1}\right)$ and $1620 \mathrm{~cm}^{-1}\left(v_{2}\right)$ corresponding to the apatite and whewellite phase, respectively. The percentages of the apatite phase thus obtained are 50, 42, 23 and $10 \%$ for KSF1, KSF2, KSF3 and $\mathrm{KSN} 1$, respectively. These results are qualitatively matched with the trend observed from powder X-ray diffraction.

\subsection{Thermo gravimetric analysis}

Thermogravimetric analysis of a whewellite phase and a mixed apatite phase were carried out. The thermogram of KSN2 is shown in figure 5. It shows weight loss in three stages at the transition temperature 160,450 and $660^{\circ} \mathrm{C}$. The observed mass losses in the three steps are $11.89,22.04$ and $30 \cdot 24 \%$, which are attributed to evolved water molecule, carbon monoxide and carbon dioxide, respectively. ${ }^{15}$ The calculated mass losses in the three steps are $12 \cdot 3$, 19.1 and $30.1 \%$, respectively, which are in good agreement with the observed values and this data confirmed the presence of monohydrated oxalate salt with high purity. Thermal analysis of a mixed phase sample (apatite) was also carried out. In this case, the thermogram is significantly different from that of 


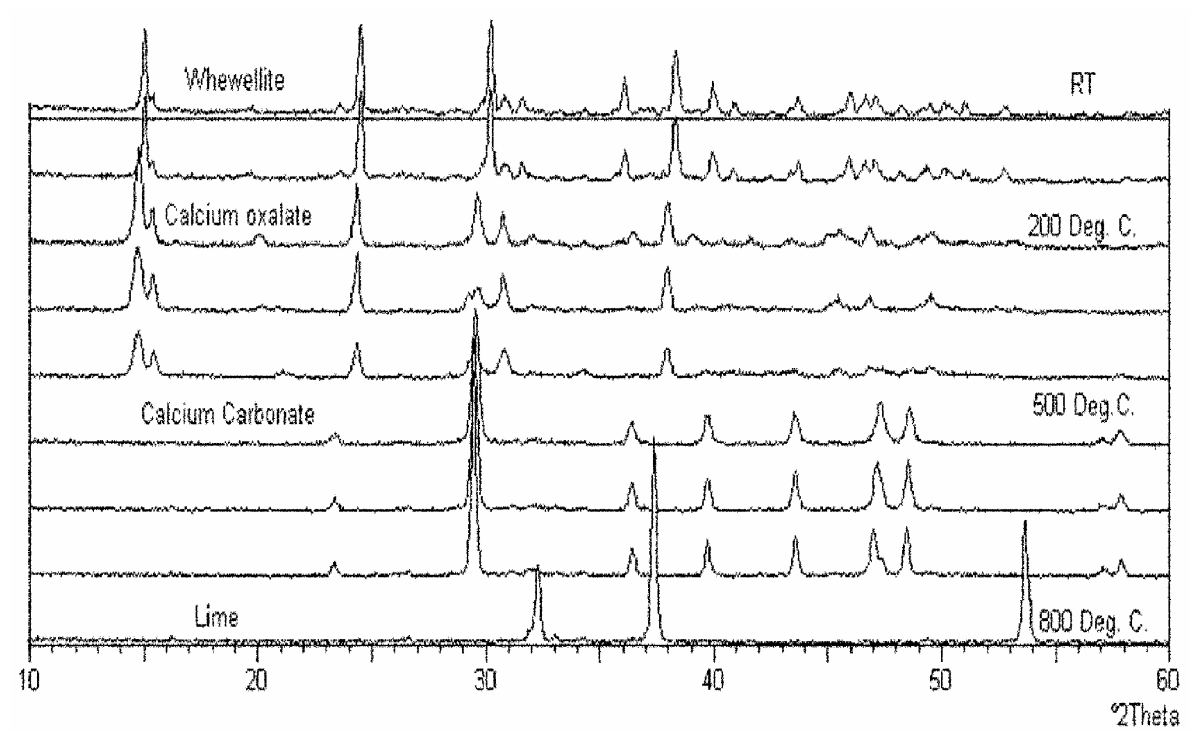

Figure 6. Variable temperature diffractograms of whewellite containing stone (KSN2).

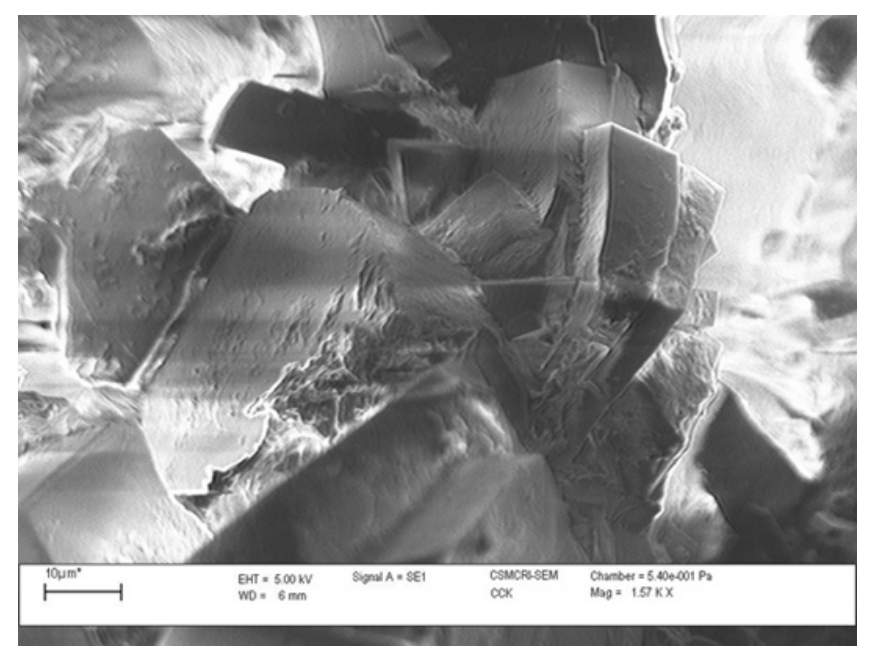

Figure 7. SEM image of the whewellite phase (KSN2).

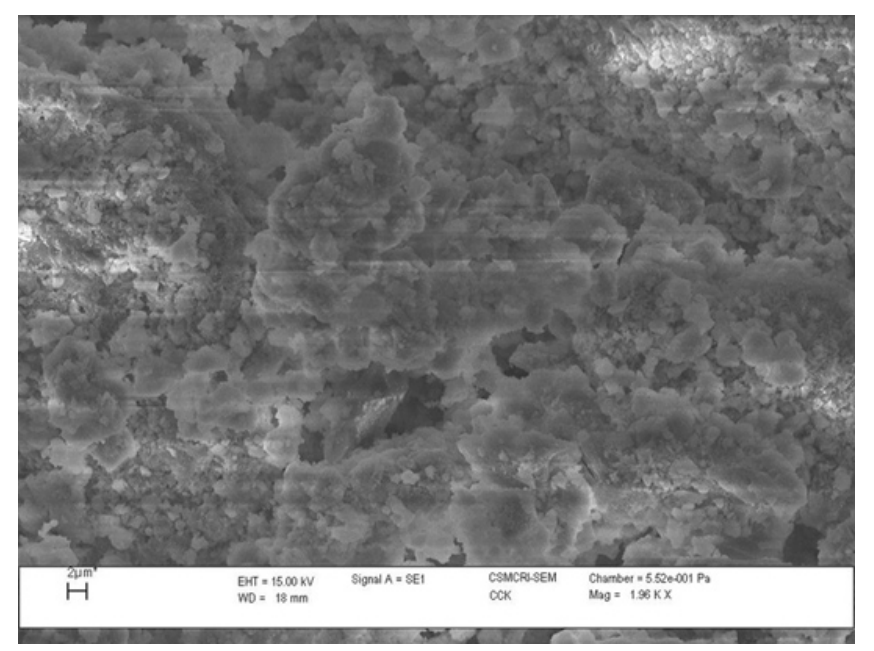

Figure 8. SEM image of apatite phase. whewellite phase, it shows four transitions, however, second and third transitions are not sharp and percentage of weight loss is low (4-10\%) compared to that of calcium oxalate monohydrate. This is obviously due to the presence of different phases ${ }^{15-17}$ with various quantities.

\subsection{Variable temperature powder X-ray diffraction analysis}

To complement the thermal analysis, variable temperature powder XRD patterns of the same sample (KSN2) was carried out. The diffractograms are shown in figure 6. It clearly shows the temperature dependent phase transformations approximately at 200, 500 and $800^{\circ} \mathrm{C}$. Comparison of these XRD patterns with ICDD-JCPDF database has revealed that the phases corresponding to 200,500 and $800^{\circ} \mathrm{C}$ are calcium oxalate (21-0838/without water), calcium carbonate (29-0305) and lime (04-0777), respectively formed by the loss of water, carbon monoxide and carbon dioxide, respectively. This observation is consistent with the result found in thermal analysis.

\subsection{Scanning electron microscopic image}

To investigate morphological aspect of the whewellite phase and that of the apatite phase, SEM images of both these samples were recorded. The micrograms are displayed in figures 7 and 8 . The image corresponds to whewellite phase (figure 7) shows high degree of cystallinity, whereas the same for apatite phase (figure 8) appears to be highly amorphous. 
The present study, therefore, suggests that the first four samples from three different patients contain almost pure phase of whewellite (trace amount of other component(s), which could not be detected by XRD and IR, may present). In the case of fourth patient, from where three stones were obtained, show the presence of mixed phases of whewellite and apatite. The case history indicates that the fourth patient has undergone through longer period of growing stones. The results, therefore, suggest initial formation of calcium oxalate monohydrate phase and probably other phases have grown with time. However, it is not clear whether the apatite phases have formed independently or the calcium oxalate monohydrate phase has been transformed into these phases with time. The latter is important, particularly in light of the observation that the sample KSF1 from fourth patient contains mainly apatite phase and the concentration of whewellite phase in this stone is very low. Mandel and Mandel have done analysis of a large number of stones and suggested a strong trend for the conversion of stone disease from calcium oxalate to calcium phosphate containing stones. ${ }^{18}$ This finding indicates the possibility of time dependent phase transformation from calcium oxalate to other phases. However, it is a complex phenomenon and the cause of phase transformation is not yet clearly known. ${ }^{18}$ Human urine itself is a complex solution consisting of calcium, magnesium, oxalate, urea, uric acid, citrate and various mucoprotines suspended in it. Their mutual interactions may change the solubility of the constituents. Presence of growth promoters and inhibitors in the urine also influence stone formation. However, discussion on this aspect requires large amount of data.

\section{Conclusions}

Constituents of eight urinary stones from four different patients have been analysed on the basis of powder XRD, IR, thermal analysis and SEM image. The present study indicates the formation of almost pure calcium oxalate monohydrate phase at the initial stage of stone formation. However, patient with multi stones and relatively older case history shows the presence of mixed phases, which indicates the possibility of time dependent phase transformation from whewellite to apatite phase. The reason in favour of this possibility arises from the study on three stones from the same patient. The concentration of calcium oxalate monohydrate phase (whewellite) decreases significantly in the order KSF3 $>$ KSF2 >
KSF1 and the concentration of apatite phase increases in the reverse order. This observation is in consistent to the remark of Mandel and Mandel. Further study on large number of kidney stones, which may provide more insight of the phenomenon, are in progress.

\section{Acknowledgements}

We thank Dr P K Ghosh for continuous encouragement and support during this work, Dr H M Mody for valuable suggestions on powder XRD study, Mr V Agarwal for recording IR spectra and Dr Mitul Doshi (urologist) for providing us some of the urinary stone samples and also information related to literature. We also thank Council of Scientific and Industrial Research (CSIR), New Delhi for generous support towards infrastructures and core competency development.

\section{References}

1. Smith L H 1989 J. Urol. Part 2141707

2. Daniel R T, Renal B, Benitz I O, Sharbaugh D M, Whipps S and Khan S R 2006 Langmuir 222450

3. Sheng X, Ward M D and Wesson J A $2003 \mathrm{~J}$. Am. Chem. Soc. 1252854

4. Finlayson B 1974 Urol. Clin. North Am. 1181

5. Ansari M S, Gupta N P, Hemal A K, Dogra P N, Seth A, Aron M and Singh T P 2005 Int. J. Urol. 1212

6. Carson P J and Brewster D R 2003 J. Paediatr. Child Health 39325

7. Herring L C 1962 J. Urol. 88545

8. Terai A, Okada Y, Ohkawa T, Ogawa O and Yoshida O 2000 Int. J. Urol. 7452

9. Mandel N S and Mandel C S 1989 J. Urol. 1421516

10. Daudon M, Doshimoni R, Hennequin C, Fellahi S, Moel G Le, Paris M, Troupel S and Lacour B 1995 Urol. Res. 23319

11. Menon M, Parulkar B G and Drach G W 1997 Campbell's urology (Philadelphia: Harcourt brace and Co) 7th edn, vol 3, p 2661

12. Estepa L and Daudon M 1997 Biospectroscopy 3347

13. Carmona P, Bellanato J and Escolar E 1997 Biospectroscopy 3331

14. Nakamoto K 1997 Infrared and Raman spectra of inorganic and coordination compounds (John Wiley and Sons, Inc) 5th edn, Part B.

15. Frost R L and Weier M L 2004 Thermochim. Acta 40979

16. Kutaish N, Aggarwal P and Dollimore D 1997 Thermochim. Acta 297131

17. Rai D V and Singh R 2005 Trends Biomater. Artif. Organs 1933

18. Mandel M, Mandel I, Kathy F, Tammy R and Mandel G 2003 J. Urol. 1692026 